\title{
CULTURAS CIUDADANAS Y PARTIDOS TRADICIONALES: ARGENTINA Y URUGUAY (1982-90)
}

Susana Mallo (*) y Miguel Serna (**)

La internacionalización creciente de las sociedades contemporáneas en sus sistemas económicos, políti$\cos$ y culturales han producido cambios en todo el continente latinoamericano. En este contexto ha surgido una creciente necesidad de estudios comparados de los países latinoamericanos.

Las posibilidades que ofrece este área de investigación interdisciplinaria, para darnos un conocimiento más cabal de las características de las sociedades contemporáneas ha sido uno de los aportes principales de las ciencias sociales hoy(1).

La consolidación todavía incipiente de las democracias en el Cono Sur es uno de los fenómenos donde los análisis comparados son útiles y pertinentes para lograr un conocimiento más acabado de las mismas (2).

La posibilidad de comparación reside como bien señala Sartori en la suposición que los casos tomados como objeto de estudio pertenecen a algún género similar de fenómenos. Lo que no quiere decir que sólo las características comunes sean objeto de comparación, la determinación de las diferencias y especificidades permiten comprender de manera más certera las similitudes observadas.

Una de las dificultades primarias que enfrenta los estudios comparativos, es la determinación del tiempo histórico a analizar. Los procesos sociales y políticos no se gestan de un día para otro, sino que tienen un proceso de maduración que lleva de algunos años a décadas.

La elección del período histórico no es una tarea fácil. Generalmente en los estudios comparados se opta por el sincronismo cronológico; sin embargo, no alcanza, es necesario un control histórico de que el período seleccionado se corresponda con procesos políticos y económicos similares.

La segunda dificultad consiste en la formación de conceptos abarcadores. La necesidad de tener a disposición teorías generales que puedan explicar más allá de fronteras geográficas, ha traído que algunas interpretaciones provenientes de las corrientes teóricas más importantes, se hayan convertido rápidamente en paradigmas no susceptibles de comprobación empírica. El problema teórico se podría plantear sintéticamente, en cómo construímos conceptos que puedan explicar "más allá de fronteras", pero que no se sustraigan a la comprobación empírica.

La tercera dificultad es de corte empírico, tiene que ver con la posibilidad de medición y las fuentes de datos. Las informaciones que se encuentran a disposición son insuficientes, heterogéneas, y no están estandarizadas. Los datos de más fácil acceso son las estadísticas electorales y otros indicadores sociales a nivel agregado.

(*) Argentina, Socióloga, Doctora en Ciencia Política, investigadora full-time y catedrática de la Facultad de Ciencias Sociales.

(**) Uruguayo, Sociólogo, graduado en sociología en el CLAEH, asistente de investigación y profesor adjunto en la Facultad de Ciencias Sociales.

(1) Elsen, Oyen. Comparative Methodology. London, International Sociological Association, 1990, p. 5.

(2) Nohlen, Dieter/Solari, Aldo. Reforma política y consolidación democrática. Venezuela, Nueva Sociedad, 1988, p. 328. 
Esto implica una limitación y a la vez un desafío para el desarrollo de investigaciones comparativas entre países. Sólo obteniendo informaciones amplias y precisas es viable un conocimiento comparado válido y seguro.

Un último problema del análisis comparado son los niveles de análisis. Si elegimos como objeto de estudio pocos países (el caso nuestro) podemos obtener un conocimiento más sustantivo y preciso sobre los mismos; contrario sensu, si se opta por comparar varios países el conocimiento será menos preciso, lo que obligaría a un tratamiento de datos más ciudadoso.

\section{I) ARGENTINA: EL DIFICIL CAMINO HACIA LA DEMOCRACIA}

El sistema político argentino ofrece al observador un panorama en el cual adquiere especial relieve el papel cumplido por los partidos. No podemos dejar de señalar la importancia histórica de los mismos pero simultáneamente corresponde asignarles una gran responsabilidad por la inestabilidad crónica que el país ha padecido desde 1930.

La formación de partidos tales como el radical - de corte liberal—, el socialista a fines del siglo XIX, o el peronista en los años 45-50 de nuestro siglo no significó en modo alguno la conformación de una cultura política que permitiera un equilibrado juego democrático.

Asimismo, la exclusión durante largos períodos de las grandes mayorías - a partir del recurrente referente autoritario simbolizado por los militaresimpidió al conjunto de la sociedad civil argentina crear y fortalecer reglas, normas y formas participativas que posibilitaran un proyecto económico, político y social viable para el conjunto de la misma.

El sistema político exhibe grandes ausencias. Por un lado la falta de un partido orgánico de derecha capaz de canalizar las demandas de las clases altas, por otro la atomización constante que caracterizó, prácticamente desde sus inicios, a los partidos de izquierda.

Como consecuencia de ello observamos estructuras partidarias ideológicamente débiles, difusas, proclives de manera persistente a la personalización de sus liderazgos y enfrentadas a un juego permanente de exclusiones.

El derrumbe del gobierno peronista en 1976 significó para los partidos la condena al "ostracismo". Esto tuvo dos importantes consecuencias: por un lado el estancamiento ideológico ante la imposibilidad de captar las transformaciones sufridas por la sociedad, por otro la ausencia de recambios - por lo menos en una primera etapa- de los liderazgos partidarios.

La crisis del régimen militar significó la reapari- ción de aquellos partidos con una fuerte ligazón con el pasado, sin embargo: "éste es un período de reequilibrio entre el momento estatal, el momento partidario y el momento societal. Los tres insustituibles e irreductibles" (3).

El período de consolidación de la democracia pasó por momentos azarosos. La situación supuso a nivel partidario la incorporación de todos los sectores sociales e ideológicos y posibilitó el arraigo de los partidos en la sociedad.

Como consecuencia, éstos comenzaron a dar respuestas creíbles a la confianza en ellos depositada y trataron de incorporar procesos de transformación y cambio que expresaran una auténtica adhesión democrática, con el consecuente abandono de prácticas tradicionales mutuas de exclusión.

Es de destacar la creciente crisis del "voto cautivo" de los partidos mayoritarios, especialmente en el partido gobernante. Encuestas de abril de 1991 nos indican que el incremento de los indecisos para las próximas elecciones llega a un $62,8 \%$ de los consultados, lo que evidentemente está demostrando una situación de despolitización o desinterés de la población. A esto debemos agregar la "alta rotatividad" o "el voto castigo" que ha sido una constante en los procesos eleccionarios realizados en los últimos años. Rastrear algunas de las principales causas de la casi constante crisis del sistema político argentino ha sido uno de nuestros propósitos.

Queremos señalar además el fenómeno de un exacerbado "presidencialismo", donde instituciones como el Parlamento o el Poder Judicial — sobre todo en los últimos tiempos- han estado supeditadas al "deseo" del Poder Ejecutivo.

Al existir un único y absorbente centro de gravedad del que emanan las órdenes y al que se subordinan las iniciativas individuales, la cualidad exigible a los hombres del presidente es la lealtad y no la imaginación. El verticalismo y la ortodoxia hacia la figura presidencial siguen siendo uno de los males históricos de los partidos políticos argentinos "y lo que es más grave también de nuestra forma de gobierno, que en los hechos prioriza el ejecutivo por encima de otros poderes del Estado y otorga al Presidente una gravitación difícil de asociar con el equilibrio republicano" (4).

1) Los primeros pasos: El gobierno de Raúl Alfonsín: 1983-1989.

El radicalismo llegaba al gobierno con un alto grado de consenso y legitimidad. El peronismo fue electoralmente derrotado por primera vez en su historia.

El liderazgo de Alfonsín se transformó en el motor del gobierno hasta 1985. Su política económica inicial no lo alejó de un reformismo redistribu-

(3) Cavarozzi, Marcelo. Partidos políticos, regímenes y transiciones democráticas. Santiago, Flacso, 1989, pág. 19.

(4) Ferrari, Alberto et. al. Los hombres del Presidente. Bs. As., Tarso, 1987, pág. 25. 
cionista; sin embargo, en el área específicamente política, el presidente lideró una serie de cambios sustanciales a los que se sumó la totalidad del partido radical.

Los derechos humanos y el juzgamiento de los culpables había de transformarse en un hecho inédito en la historia del país. Asimismo, en este período, el gobierno radical intentó transformar la estructura de corte corporativo del sindicalismo tradicional. Para ello, envió al parlamento un proyecto de ley destinado a reorganizar los mecanismos de acción y representación sindical. El fracaso parlamentario de dicha ley, así como la incapacidad del gobierno, hicieron evidente que el radicalismo poseía escasa capacidad para la reformulación de las políticas públicas así como pocas posibilidades de generar agregación de intereses.

Es decir, se visualizó un estado débil frente a las poderosas corporaciones capaces de organización y de dar respuesta. Afirma Cavarozzi que el gobierno radical eligió para este período la confrontación, y como escenario el parlamento sin medir adecuadamente sus fuerzas.

Se suma a ello que el "talón de Aquiles" del país: la economía, no pudo ser solucionado. Un nuevo equipo económico logró condensar la gestión económica además de asumir todas las iniciativas en materia política.

Los resultados de esta política económica significaron la marginación de los políticos tradicionales del partido y la aparición de una combinación de técnicos extrapartidarios asociados a un conjunto de jóvenes pertenecientes al núcleo alfonsinista, quienes asumieron mayores responsabilidades políticas. Esto tuvo como consecuencia una casi total simbiosis entre el proyecto gubernamental y los sectores juveniles, quienes perdieron toda autonomía en su discurso y en su posibilidad de crítica hacia el gobierno. Las consecuencias fueron no sólo la pérdida de un perfil propio, sino también la pérdida de credibilidad del electorado.

2) "Voto castigo" la respuesta desde la sociedad civil.

Un partido peronista recompuesto, con nuevas figuras y nuevas propuestas derrotó -el 6 de septiembre de 1987 - a un radicalismo que no encontraba el rumbo para su campaña electoral. El peronismo ganó en 15 provincias, incluyendo la reelección de Menem en su provincia por cifras abrumadoras.

El radicalismo finalizaba su mandato con un mapa político totalmente opositor y el "voto castigo" consolidaba su presencia.

¿Qué ha sucedido con la política argentina? Ciertamente se han variado las reglas prácticas pero, a cambio, no ha podido reconstruirse "el intercambio político como un sistema de acción colectiva en el cual los diferentes protagonistas ponen en juego el sentido de su acción en una lógica de reciprocidad de la cual puede salir confirmada, redimensionada o desmentida la propia identidad" (5).

Evidentemente, ambos partidos repitieron y repiten políticas de exclusión que no permiten la constitución de identidades, lo que es una fuente permanente de frustraciones y derrota de los sectores más progresistas. Dentro de estas variables debemos incorporar al nuevo candidato peronista.

A lo largo de 1988 la figura de Carlos Menem, con un pequeño grupo de operadores, comenzó de manera creciente a aparecer en el ámbito nacional. De político provincial ingresó al ámbito nacional. El triunfo de Menem en las elecciones internas de julio de 1988 produjo una enorme conmoción y sorpresa; no sólo dentro del peronismo, sino también fuera de él. Las cifras son claras: logró el 54,3\% de los votos y los renovadores sólo el $45,7 \%$ de ellos.

Su opositor político: Eduardo Angeloz, tecnoburócrata de imagen "ejecutiva" que conjugaba un modelo modernizador y neoconservador de corte elitista. La falta de carisma personal y la creciente impopularidad del gobierno llevó a la derrota del partido radical.

A todo este cuadro debe sumarse la "Ley de Punto Final" la cual habría de recibir duras críticas de las organizaciones de "Derechos Humanos", de sectores del partido radical y el repudio de segmentos de la sociedad civil. Sin embargo, es de destacar que este rechazo no se vio reflejado en grandes protestas o movilizaciones, lo cual suponemos que se debió al creciente desencanto de la población, la cual se sintió una vez más excluída de la toma de decisiones.

En este clima opresivo se da otro acontecimiento que habría de perturbar aún más al conjunto de la sociedad, hacemos referencia a los hechos de "La Tablada". Un pequeño grupo, en enero de 1989, se apodera del cuartel que lleva su nombre y en un acto - aún inexplicado - convoca a la rebelión popular. La sangrienta represión por parte del ejército puso fin a esta aventura, pero esto también implicó que se agitaran los fantasmas de la "subversión" agazapada, permitiendo al ejército recomponer sus funciones de "custodio del orden". Así, el Poder Ejecutivo, delegará en el ejército y no en la policía - como se había estipulado en 1983- la represión de la llamada "subversión interna". Reaparecen así los viejos sistemas de control y "demonización del otro".

3) El retorno del peronismo. Como era previsible las elecciones del 14 de mayo de 1989 fueron un rotundo triunfo para el candidato peronista. Cabe señalar que el Partido Intransigente apoyó la fórmula peronista, pese a que la figura de Menem no resultaba del todo "creíble". La mayoría de la dirección del P.I.

(5) Rusconi, G. M. “Modernidad post-modernidad”. Rev. La ciudad futura, Bs. As., Núm. 14, 1989 , pág. 40. 
"prefirió no incurrir en el idealismo de adaptar su práctica a sus ideas y optó por modificar estas últimas" (6).

El 8 de julio C. Menem asumió la presidencia. Semanas antes, al anunciar su gabinete, habían comenzado las sorpresas: el nombramiento del ministro de Economía recayó sobre uno de los directores principales de la multinacional "Bunge y Born", Miguel Roig. Otra sorpresa fue el nombramiento de un enemigo tradicional del peronismo: Alvaro Alzogaray como el principal asesor económico presidencial.

De ahí en más el discurso menemista sufrió un cambio radical. Su programa económico tomó rápidamente un tono neoliberal clásico y sus propuestas de privatizaciones, ajustes monetarios y achicamiento del Estado se transformaron en el eje estructurador de su política. También, como en el caso del radicalismo, los sectores jóvenes debieron readecuar su discurso y su práctica política, a excepción del "Grupo de los 8" que se constituyó en un núcleo rebelde.

El contexto de incertidumbre se acrecienta y los espacios estatales se transforman rápidamente en arena de conflicto tanto intra como extra partidarios.

El desafío a las instituciones es grande. Existen elementos preocupantes para el conjunto de la sociedad civil argentina. En este marco señalaremos, además, un creciente y peligroso escepticismo hacia la política y los políticos. Un manto de descreimiento cubre gran parte de la sociedad.

$\mathrm{El}$ indulto a los militares, pese a que un $72 \%$ de la población se oponía a ello - medido por encuestassumado a denuncias por parte del embajador norteamericano de solicitud de prebendas por parte de altos funcionarios, no han por cierto ayudado a la imagen gubernamental. La corrupción es hoy en día un lugar común en la Argentina (*).

La ruptura de la articulación entre liberalismo y democracia y la adopción de un modelo capitalista atado a un proyecto conservador significa en términos gubernamentales: "la economía popular de mercado inspirada en la reformulación del modelo pragmático del justicialismo respetando los valores perennes del mismo (7).

4) Los desafíos de la gobernabilidad. En este panorama no demasiado alentador, entre agosto y octubre de 1991, el gobierno deberá afrontar la primera compulsa electoral. Si bien pensamos que el voto castigo hará su reaparición, quizás éste no golpee tan duramente al peronismo. En este sentido debemos destacar que, efectivamente, se ha consolidado en el país un bipartidismo; aunque éste se halla aún muy lejos de un auténtico proceso de recomposi- ción de sus estructuras y de formas realmente representativas. El fenómeno del liderazgo personalizado continúa siendo una forma primaria en que se estructura el sistema político argentino.

Lo cierto es que pese a la falta de credibilidad tanto del peronismo como del radicalismo, no es ésta la primera vez que atraviesan agudas crisis y procesos de cuestionamiento de sus respectivas identidades. Tal como señala De Ipola, esto se ha logrado gracias a su maleabilidad ideológica, su experiencia o la simple inercia, lo que ha permitido a dichos partidos superarlas sin gran daño.

La consolidación de un bipartidismo responsable con una clara ausencia de partidos de izquierda como de derecha, en un contexto de democracia débil, es un logro histórico que merecerá profundos análisis.

Es de señalar que la sociedad civil ha tenido por primera vez en 50 años- la posibilidad de utilizar su voto como elemento de "premio" o "castigo" a los gobernantes. Esto significa sin duda un afianzamiento de la sociedad civil y también un aprendizaje de la sociedad política.

Por último queremos enfatizar la alta rotatividad acaecida en las últimas cuatro elecciones que tuvieron lugar en Argentina; exceptuando la de 1985, en la cual el electorado se mantuvo bastante estable, en el resto de las elecciones el "voto castigo" ha quebrado la hegemonía parcial que poseían los partidos gobernantes. Que la democracia no ha traído la cuota de certidumbre por todos deseada es un hecho irrefutable; sin embargo, "inaugura una historia en la cual los hombres hacen la experiencia de una indeterminación última en cuanto al fundamento del poder, de la ley y del saber, y al fundamento de la relación del uno con el otro, en todos los registros de la vida social" (8). En definitiva, la posibilidad de articulación entre sectores progresistas en distintos niveles, como así también en distintas instancias de participación y deliberación, habrá de determinar la posibilidad de recrear ámbitos de gobernabilidad.

\section{II) CONTINUIDADES Y RUPTURAS EN EL TRANSITO HACIA LA DEMOCRACIA EN URUGUAY}

Los partidos tradicionales blanco y colorado, divisas originadas durante la denominada "Guerra Grande", acuñaron desde entonces el calificativo de partidos "tradicionales" (pp.tt.), constituyendo al mismo tiempo parte importante de la conciencia nacional de este país.

Los partidos tradicionales constituyeron el núcleo de un sistema bipartidista estable. Partidos "catchall”, pluriclasistas: el colorado más liberal, cosmopo-

(6) De Ipola, E. “Posibilidades y límites del centroizquierda en la Argentina”, en La Ciudad Futura, Núm. 22,1990 , pág. 9.

(*) Tema harto espinoso, sobre todo por la utilización que de esto hace la derecha, desprestigiando la política y los políticos.

(7) Curia, Eduardo. El cronista comercial, 20/V/90.

(8) Lefort, Claude. La invención democrática, Bs. As., Nueva Visión, 1990, pág. 158. 
lita, anticlerical, de base urbana, afirmado en el Estado y el desarrollo industrial; el blanco o nacional de origen rural, apoyando en la clase alta tradicional, el pluralismo social, la afinidad latinoamericana, siendo más liberal económicamente y conservador políticamente. Durante el S. XX estos partidos controlaron alrededor del $90 \%$ del electorado.

Una democracia que se había sostenido en una modernización económica temprana, una estabilidad política consolidada durante el S. XX con la extensión de los derechos políticos anticipándose al resto de los países de la región, sin clivajes étnicos, con indicadores sociales positivos, y apoyada en un Estado benefactor y una clase dirigente con importante autonomía de sectores corporativos.

Esta democracia entra en una profunda crisis económica, política y social durante las décadas del "60 y 70". Lo cierto es que se dio un "vacío de poder" (9) del cual ningún partido se responsabilizó y el cual dio lugar a una lenta pero firme intervención militar.

La dictadura militar que se instauró en 1973 significó la sustitución por primera vez en casi un siglo de los partidos como actores centrales de la política uruguaya (10).

El rechazo al proyecto militar en el plebiscito de noviembre de 1980 puso nuevamente a los partidos políticos en el centro de la escena política, comenzando un lento y firme proceso de redemocratización.

b) La administración batllista de la transición. 1984 fue el año clave para el logro de un acuerdo mínimo entre militares y políticos sobre las condiciones de traspaso del poder político. Acuerdo difícil de alcanzar, al que no adhirió el partido nacional y que para realizarlo los militares tuvieron que convocar y desproscribir a parte significativa de los partidos de izquierda.

El partido colorado triunfa en las elecciones de 1984, principalmente la fracción batllista que alcanzó el $76,4 \%$ de los votos partidarios y el $30,5 \%$ del electorado nacional.

El batllismo tuvo un papel moderador y negociador en todas las instancias de diálogo con los militares para una salida democrática. Una opción opositora, democrática y moderada que rememoró mucho de la "mesocracia batllista" (11).

El pachequismo declinó notoriamente su caudal electoral (pese a la victoria colorada) tanto dentro de su partido como sobre el total del electorado. La U.C.B. mostró un líder avejentado que evitó los debates políticos y que el apoyo brindado a la dictadura militar lo hizo muy impopular en momentos de reconstrucción de la democracia.

Sin duda la dificultad más importante que tuvo que afrontar el partido nacional en las elecciones de 1984 fue la proscripción de su principal líder, Wilson Ferreira. La mayoría nacionalista defendió una salida democrática que permitiera la participación de Ferreira, mientras que el gobierno militar vetó esa posibilidad; alejando y excluyendo al partido de las negociaciones políticas para la transición hacia la democracia. A pesar de todo las corrientes políticas que apoyaban el liderato de Ferreira mantuvieron su peso político, mientras los sectores progubernamentales sufrieron un claro rechazo de la ciudadanía nacionalista.

El gobierno de J. Ma. Sanguinetti se manejó de forma pragmática en las soluciones gubernamentales a las principales reivindicaciones que estaban pendientes en la transición democrática. Con un estilo claramente mesocrático fundamentalmente los dos primeros años, intentó satisfacer a la mayor parte de los sectores de la sociedad civil.

Es así que en esos años de mandato gubernamental la toma de decisiones en materia de política económica se inspira en modelos desarrollistas, reivindicando la orientación estatal y llevando a cabo medidas de redistribución de riqueza. Sin embargo conforme se afirmaba en la gestión gubernamental volvieron a aparecer medidas económicas afines a esquemas teóricos neoliberales.

Los Derechos Humanos (DD.HH.) fueron uno de los hitos que pautaron el paso de la transición a la consolidación (o no) de la democracia.

Los presos políticos fueron liberados en marzo de 1985, a través de una Ley de Amnistía, y los institutos jurídicos del indulto y la gracia. Al año siguiente los partidos políticos se vieron presionados corporativamente por los militares para darle respuesta a la situación de los implicados en las violaciones de los DD.HH. durante la dictadura militar. Los acontecimientos mencionados culminaron con la aprobación de una amnistía total a los violadores de los DD.HH. en diciembre de 1986, con la denominada "Ley de caducidad de la pretensión punitiva del Estado".

Casi inmediatamente como respuesta repentina desde la sociedad civil se constituye la Comisión Nacional Pro Referéndum (C.N.P.R.) de integración heterogénea, que recibió adhesiones no sólo de partidos opositores y movimientos sociales, sino también de importantes fracciones de los pp.tt.; el caso más notorio fue el

(9) El concepto alude a la carencia de una élite política dirigente con un proyecto de desarrollo nacional capaz de obtener consenso social. Real de Azúa, Carlos. Uruguay, ¿una sociedad amortiguadora?, Montevideo, F.H.C., 1984, pág. 86-87.

(10) Pérez, R.-Rilla, J. y Caetano, G. "Cambios recientes en el sistema político uruguayo concebido como una partidocracia" en Los Partidos Políticos de Cara al 90, Montevideo, F.C.U., 1989, pág. 33.

(11) La "mesocracia batllista" fue definida por la existencia de una elite dirigente político partidaria que desde el Estado ejerció un papel redistributivo, arbitrando y dando concesiones a los diversos sectores sociales. En confluencia con la misma se constituyó una sociedad con predominio de sectores medios y una ideología de clase media, en la que el compromiso y el consenso poseían un poder de convocatoria mayor que la polarización y el conflicto social. Real de Azúa, Carlos. Uruguay, ¿una sociedad amortiguadora?, Montevideo, F.H.C., 1984, pág. 53. 
del Movimiento Nacional de Rocha (M.N.R.) en el partido nacional.

Los sectores mayoritarios de los pp.tt. que habían votado la ley de caducidad entorpecieron y enfrentaron en muchos casos las actividades de la C.N.P.R., principalmente por parte del partido colorado en el recuento de firmas. Lo que les significó una pérdida de credibilidad ante la opinión pública y de legitimidad ciudadana.

Los resultados fueron elocuentes: si el voto amarillo triunfó a nivel nacional sobre el verde con una ventaja del $14,7 \%$, esta relación se invirtió en la capital del país en un $12,4 \%$ a favor del voto verde.

c) La consolidación de las reglas democráticas. Las elecciones de 1989 son las primeras realizadas en forma libre y normal desde 1966 (12). Revisten por tanto relevancia en la consolidación del régimen democrático.

El batllismo llegó a las elecciones del 89 desgastado y dividido, lo que se reflejó en los resultados obtenidos. De ser una mayoría aplastante dentro del partido volvió a controlar la mitad de las simpatías coloradas. Más grave fue su peso relativo en el conjunto del electorado nacional donde sufrió las consecuencias del "voto castigo", captando un 14,9\% (apenas la mitad de los votos obtenidos en 1984).

El pachequismo tuvo un repunte muy importante en términos electorales, dentro del partido y a nivel nacional. Influyó en tal sentido que fue una de las principales agrupaciones que impulsó el plebiscito a favor del reajuste cuatrimestral de las pasividades. El segundo factor político fue la renovación de líderes con la figura de P. Millor cuya lista logra captar el $44 \%$ de los votos pachequistas.

El herrerismo se reunifica, constituyendo una nueva mayoría dentro del partido junto al ex-sector wilsonista (Por La Patria), Renovación y Victoria obteniendo el $58,1 \%$ de los votos partidarios y el $37,6 \%$ del electorado nacional.

La fórmula presidencial triunfante se distancia considerablemente de la colorada precedente. Sus ejes programáticos consistieron en llevar adelante cambios sustanciales del estado y la sociedad, inspirándose en corrientes de pensamiento modernizantes y neoliberales.

El M.N.R. le permitió mantener el carácter "catchall" al partido nacional recogiendo parte del electorado de centro-izquierda así como simpatizantes del voto verde.

Como conclusión general, si en las elecciones del 84 había triunfado el voto moderado, la mesocracia batllista, las elecciones del 89 premian las posiciones políticas más polarizadas quebrando así el continuo derecha-izquierda.

d) Los cambios principales en el sistema de partidos.
1.-La rotación de votantes entre los partidos tradicionales. A partir de 1958 se producen cambios en el sistema de partidos que van a alterar profundamente la competencia por el electorado flotante y el denominado "voto útil". El ascenso al gobierno del partido nacional marcó la alternancia efectiva de los partidos en la dirección estatal.

Hecho al que debemos agregar la irrupción de nuevos actores políticos. En este contexto la rotación de votantes asume un rol relevante para la competencia política.

Desde esa fecha la alternancia efectiva en el poder político entre los dos partidos se consolida mucho más: de 7 instancias electorales 4 fueron ganadas por el partido blanco y 3 por el colorado, triunfos que no fueron consecutivos sino intercalados, con lo que la rotación de votos aumenta.

En tal sentido y limitándonos al período de análisis construimos un coeficiente de rotación (ver cuadro anexo n. ${ }^{\circ}$ ) donde se aprecia el crecimiento notorio de la rotación de votantes en las últimas tres instancias electorales.

Entre las elecciones internas del 82 y las últimas elecciones del 89, la cantidad porcentual de votantes rotantes se duplica (de un 5\% pasa a 10\%), que en la realidad fue mucho mayor debido al que el coeficiente de rotación sólo mide saldos netos de rotación global entre partidos.

La alta rotación de votantes entre los pp.tt. es confirmada según datos de una encuesta realizada por Equipos Consultores, publicada en Búsqueda el $8 / 3 / 90$. Se encuentra que entre quienes optaron por la fórmula presidencial Lacalle-Aguirre, el $32 \%$ en Montevideo y el $20 \%$ en el interior habían votado al partido colorado en las elecciones de 1984.

La rotación de votantes tuvo repercusión también en la alternancia de los pp.tt. en los poderes locales. En 1984 el partido colorado había logrado 12 intendencias, mientras que las 7 restantes fueron adjudicadas al partido blanco. En 1989 de las 19 intendencias, el partido blanco obtiene 16 , mientras el colorado apenas mantiene las de 2 departamentos.

Estas tendencias de alta rotación de votantes entre los partidos blanco y colorado lleva consigo cambios importantes en la cultura política. Pese a que siempre fueron vistos como partidos de "colcha de retazos" la rotación de votos entre ambos no alcanzaba a afirmar lo mismo, existía la tradición colorada por un lado y la lealtad blanca por otro.

Las últimas elecciones registran una pérdida de lealtades políticas. No se trata simplemente que los electores elijan indistintamente a representantes blancos o colorados, sino que se están desfigurando y desgastando las lealtades de los votantes tradicionales a cada uno de los partidos.

(12) Pablo Mieres. "Las elecciones de 1989 en Uruguay: un sistema de partidos en transición", Montevideo, Cuaderno del Claeh, Núm. 53, 1989, pág. 7. 
2.-Disminución de la convocatoria electoral de los pp.tt. La rotación de votantes entre los pp.tt. y la generalización del "voto castigo" no conlleva necesariamente un desgaste político-partidario; es más, muchas veces beneficia a la competencia política y la libertad de elección de los ciudadanos. Sin embargo en el caso uruguayo no parecen ser esas las consecuencias sobre los pp.tt.

En esta sección analizaremos tendencias al debilitamiento de los pp.tt. como actores hegemónicos del sistema de partidos.

i) Débil captación del "votante joven" por parte de los pp.tt.: en una encuesta realizada en 1985, L.E. González se preguntaba acerca de cuáles eran las bases sociales de los partidos políticos uruguayos. Uno de los resultados más interesantes que surgieron de la investigación fue la fuerte relación entre edad y voto partidario.

Los jóvenes votantes optaban ampliamente por los partidos de izquierda, en aquel momento en la coalición Frente Amplio: el 55\% de los menores de 30 años (en edad de votar) optaron por la coalición política. Contrario sensu los votantes de los pp.tt. en especial del partido colorado eran desproporcionadamente viejos; la relación era inversa, el $50 \%$ de los votantes de 60 y más años votaron a los colorados.

Estas tendencias fueron reafirmadas en las últimas elecciones. Remitiéndonos nuevamente a la encuesta de Equipos Consultores, los que votaron por primera vez corresponden apenas entre el 0 y $10 \%$ de los votantes de las principales fracciones de los pp.tt. Por el contrario los partidos de izquierda muestran una importante renovación de votantes correspondiendo entre el 9 y $15 \%$ de nuevos electores.

La pérdida de nuevos votantes por parte de los pp.tt. no es simplemente un hecho demográfico. Implica profundas transformaciones en la cultura cívica del electorado nacional. La baja captación de jóvenes votantes es un indicador de que los pp.tt. no están siendo agentes de socialización política convocantes de esos estratos sociales.

El peso excesivo de votantes viejos en los pp.tt. muestra que sólo logran mantener los votantes ya socializados en las tradiciones blanca y colorada.

ii) Las izquierdas políticas como alternativas electorales. El crecimiento electoral y el n. ${ }^{\circ}$ de partidos de las corrientes no tradicionales, en especial de izquierda, es una tendencia de largo plazo que surge

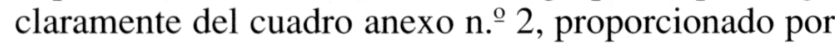
Mieres.

Los partidos no tradicionales de disputarse en el pasado alrededor del $10 \%$ del electorado restante no controlado por los pp.tt. llegan a captar en 1989 el $30,8 \%$ del electorado nacional y un $47,6 \%$ de votantes montevideanos.
Los pp.tt. que constituían un sistema bipartidista estable sufren un continuo desgaste y traspaso de votantes hacia partidos no tradicionales. Así mientras que el porcentaje de votantes obtenidos por los pp.tt. en 1982 alcanzaba al 91,03\% del electorado nacional, éstos fueron disminuyendo progresivamente su caudal electoral hasta las últimas elecciones donde apenas logran captar el 69,2\%.

Tenemos entonces un sistema de partidos con grandes modificaciones que desde 1971 deja de ser bipartidista y se transforma en multipartidista, con cuatro actores políticos relevantes (13). Cambios reconocidos de manera explícita por los pp.tt. a través de la aprobación legal (3/10/89) que otorgaba la calidad de lemas permanentes al Frente Amplio y al Partido por el Gobierno del Pueblo.

\section{III) CONCLUSIONES PRELIMINARES}

Señalamos para Argentina un rápido retorno a la democracia luego del fracaso de los militares en la guerra de Las Malvinas; esta democratización no se consolida, existiendo continuos desequilibrios económicos y políticos.

La transición en Uruguay es considerablemente diferente, siendo mucho más lenta, pero logrando a largo plazo una consolidación mayor del sistema político.

- Los partidos radical y peronista muestran unidad y verticalismo en su accionar político tras liderazgos fuertes.

Los pp.tt. uruguayos en cambio aparecen con mayor pluralismo interno de corrientes políticas, lo que reditúa a su vez en una alta fraccionalización de los mismos.

Otra característica del funcionamiento interno de los partidos argentinos es la frecuencia en la formación de acuerdos cupulares y prácticas de clientelismo político.

Los pp.tt. uruguayos se diferencian apreciablemente, mostrando una mayor transparencia en la actividad política, así como una marcada democratización interna.

- La imposibilidad de los partidos tradicionales de ambos países de una renovación de sus estructuras partidarias, impidió que los jóvenes dirigentes políticos que poseían hacia el 84-87 nuevas y atractivas propuestas, fueran absorbidos por la estructura de poder partidario. Lo que significó para los mismos un retroceso o incluso derrotas en los procesos electorales posteriores.

- La responsabilidad en el juzgamiento de las violaciones de los DD.HH. en Argentina fue radical, siendo el único país del Cono Sur que pudo llevar a cabo un juzgamiento efectivo de los responsables de las mismas.

(13) Una buena discusión de los criterios teóricos (en especial del criterio numérico) para diferenciar sistemas de partidos se encuentra en G. Sartori. Partidos y sistemas de partidos, tomo 1, Madrid, Alianza, 1980. 
Sin embargo al poco tiempo se suscitaron varias rebeliones militares, así como el resurgimiento de la sedición. Lo que no sólo dejó pendiente el tema del respeto de los DD.HH. sino que hizo también tambalear las instituciones democráticas.

Las soluciones en Uruguay fueron mucho más gradualistas. Los presos políticos fueron liberados a través de una amnistía general, mientras que aquéllos que cometieron delitos de sangre fueron liberados a través de la concesión de indultos y gracias. Por otra parte los militares y civiles responsables de violaciones a los DD.HH. tuvieron que esperar dos años más para que se les otorgara una amnistía general.

Mientras que en Argentina los militares continuaron siendo actores centrales en la toma de decisiones políticas, en Uruguay éstos se replegaron de la escena política sin provocar rebeliones, pero manteniendo vetos y reivindicaciones propias de la institución castrense.

- En ambos países durante el período de la transición encontramos ofertas políticas que centran sus propuestas económicas y sociales en modelos desarrollistas con cierta redistribución de la riqueza.

Es recién a partir de 1986, momento en que logran cierta estabilidad los gobiernos constitucionalmente elegidos, que comienzan a hegemonizar las propuestas políticas modernizantes y neoliberales.

Partidos y corrientes políticas que se inspiran y justifican su acción de acuerdo a los discursos políticos modernizantes y de inspiración neoliberal que son hegemónicas en los países más industrializados.

- Tanto en Uruguay como en Argentina se generalizan procesos electorales de "voto castigo" y alta rotatividad entre los votantes de los partidos tradicionales.

Pero mientras que en Argentina no se registra una pérdida relativa en el caudal electoral de los partidos tradicionales, en Uruguay la disminución constante de votantes en los últimos años es muy apreciable.

La alta rotación de votantes, nos muestra una dinámica electoral propia de los sistemas políticos contemporáneos.

Asimismo la pérdida de credibilidad en las lealtades tradicionales es un síntoma de excepticismo de la sociedad civil en relación a las respuestas provenientes del sistema político.
- Para el caso argentino y pese a todos los vaivenes políticos a lo largo del período, logró reconstruir un sistema bipartidista, con una notable ausencia de partidos de derecha y de izquierda.

En Uruguay en cambio se dan importantes transformaciones en el sistema de partidos pasando de un bipartidismo a un sistema multipartidista. Es notorio el crecimiento del peso relativo de los partidos de izquierda en el sistema político.

La consolidación de un bipartidismo responsable en Argentina, y respectivamente de un multipartidismo efectivo en Uruguay, en un contexto regional de crisis económicas y conflictos sociales es un logro histórico de ambos procesos de redemocratización que no podemos dejar de reconocer.

- Para el caso argentino este bipartidismo determina un "voto cautivo" que a nuestro entender impide experiencias de auto-organización popular. En un país donde el entramado social resiste importantes procesos de disgregación y segmentación, es fundamental la consolidación de formas participativas que aseguren canales de representación especialmente para los sectores más postergados.

En Uruguay la mayor capacidad de organización y respuesta política de la sociedad civil (el caso más amplio la Comisión Nacional Pro Referéndum) mostraron la vigencia de la recolección de firmas, organización de plebiscitos, y ejercicio de sus derechos cívicos a través del voto, como los canales fundamentales de participación ciudadana.

A lo que debemos agregar un crecimiento de la izquierda como alternativa de poder, desde el que se vislumbran nuevas formas de participación política de los sectores populares, siendo al mismo tiempo uno de los desafíos futuros para la consolidación del sistema político.

Nuestra aspiración para estos países que han sufrido procesos tan traumáticos es la constitución de "una sociedad donde los movimientos forjan libremente las opciones políticas, donde no son obstáculos para elaborar los principios políticos o las jerarquías de los temas sociales, donde recomiendan a los partidos y al estado cómo llevar a cabo sus expectativas sociales, la máxima de la "autogestión humana", que está relativamente aparte de la gestión o administración de las cosas, puede llegar a ser cierta" (14). 
CUADRO N. 1

\section{COEFICIENTE DE ROTACION DE VOTOS ENTRE LOS PARTIDOS TRADICIONALES}

Rotación de votantes en Argentina
1983-1985

0,05

0,15

0,07

Rotación de votantes en Uruguay

1971-1982 1982-1984

1984-1989

0,05

0,08

0,10

\section{BIBLIOGRAFIA}

Catterberg, E.: “El sistema de partidos políticos y la transición hacia la democracia argentina”. En González Casanova P. compilado “Estado y sociedad en América Latina”, México, Siglo XXI, 1989.

Cavarozzi, Marcelo: Partidos políticos, regímenes y transiciones democráticas, Santiago, Flacso, 1989.

Cavarozzi, M. y Grossi, M.: "La frustrante experiencia de los partidos en el manejo de la transición” en Partidos políticos de cara al 90, Montevideo, FCU, 1989.

De Ipola, E.<; "Posibilidades y límites del centroizquierda en la Argentina” en La Ciudad Futura, Núm. 22, 1990.

Elsen, Oyen: Comparative Methodology London, International Sociological Association, 1990.

Fabregat, J. T.: "Elecciones Uruguayas", Cámara de Senadores, 1971.

Ferrari, Alberto: Los hombres del Presidente, Bs. As., Tarso, 1987.

González, L. E.: "Los partidos y la redemocratización en Uruguay”, Montevideo, Cuaderno del Claeh, Núm. 37, 1986.

Tesis de doctorado, Montevideo, selección publicada por Búsqueda.

Hague, R./Harrop, M.: Comparative goverment and politics London, Ed. Macmillan, 1987.

Heller, Agnes y Feher, Ferenc: Políticas de la Postmodernidad Barcelona, Ed. Península, 1989.

Jamenson: "Las políticas de la teoría. Posiciones ideológicas en el debate post-modemista” en Rev. Fahrenheit 450, n.ํㅡ 1, Bs. As., 1986.

Lefort, Claude: La invención democrática, Bs. As., Nueva Visión, 1990.

Mieres, Pablo: "Las elecciones de 1989 en Uruguay: un sistema de partidos en transición”, Montevideo, Cuaderno del Claeh, Núm. $53,1989$.
El coeficiente de rotación fue construído a partir de los resultados electorales, razón por la cual ya que se trabajó sobre datos agregados lo que mide es el mínimo de rotación de votantes, expresado porcentualmente sobre el total de votos de los partidos tradicionales en la última elección.

El supuesto principal que permitió su confección fue la estabilidad relativa de los electorados de cada partido político.

El coeficiente fue elaborado por el Licenciado Miguel Serna con el asesoramiento de Miguel Galmes, Director del Instituto de Estadística de la Facultad de Ciencias Económicas y Administración.

\section{CUADRO N.ㄴ 2}

\section{EVOLUCION ELECTORAL DE LOS PARTIDOS TRADICIONALES Y LOS NO TRADICIONALES (\%)}

\begin{tabular}{lrrrrr}
\hline & 1962 & $\mathbf{1 9 6 6}$ & $\mathbf{1 9 7 1}$ & $\mathbf{1 9 8 4}$ & $\mathbf{1 9 8 9}$ \\
\hline Partidos tradicionales & 91,0 & 89,8 & 81,2 & 76,3 & 69,2 \\
\hline Partidos no tradicionales & 9,0 & 10,2 & 18,8 & 23,7 & 30,8 \\
\hline
\end{tabular}

Mazzorin, Ricardo: "Capitalismo y reforma del estado: una disgresión”. En Rev. La ciudad futura, n.. 22, 1990.

Nohlen, Dieter/Solari, Aldo Reforma política y consolidación democrática Venezuela, Nueva Sociedad, 1988.

Nun, José: La situación de los sectores populares en el proceso argentino de transición a la democracia, Mimeo, Bs. As., CLADE, 1988.

Panebianco, A.: Modelos de partido, Madrid, Alianza, 1990.

Pérez R. Rilla J. y Caetano, G.: "Cambios recientes en el sistema político uruguayo concebido como una partidocracia" en Los Partidos Políticos de Cara al 90, Montevideo, F.C.U., 1989.

Portantiero, J. C.: "La crisis argentina una mirada retrospectiva" en Ensayos sobre la transición democrática en Argentina Bs. As., Punto Sur, 1987.

Rama, G.: La democracia en Uruguay, Montevideo, GEL.

Real de Azúa, Carlos: Partidos, política y poder en el Uruguay, Montevideo, F.H.C., 1989. 1984.

Uruguay, ¿una sociedad amortiguadora?, Montevideo, F.H.C.,

Rial, J.: Partidos políticos, democracia y autoritarismo, tomo 2, Montevideo, E.B.O.

Uruguay: Elecciones de 1984, Montevideo, E.B.O., 1985.

Rusconi, G. M.: "Modernidad post-modernidad", Rev. La ciudad futura, Bs. As., Núm. 14, 1989.

Sartori, G.: Partidos y sistemas de partidos, tomo 1, Madrid, Alianza, 1980.

La política. Lógica y métodos en las ciencias socialos, México, F.C.E., 1987. 


\section{RESUMEN}

1.-En Argentina se da un rápido retorno a la democracia, democratización que no se consolida existiendo continuos desequilibrios económicos y políticos.

La transición en Uruguay se diferencia considerablemente siendo mucho más lenta, pero logrando a largo plazo una consolidación mayor del sistema político democrático.

2.- Argentina pese a todos sus vaivenes políticos a lo largo de su historia, logró reconstituir el sistema de partidos bipartidista (radicales y peronistas) con una notoria ausencia de partidos de derecha y de izquierda.

Uruguay en cambio tiene importantes transformaciones del sistema de partidos, pasando de un sistema bipartidista (blancos y colorados) a uno multipartidario. Es notorio el crecimiento del peso relativo de los partidos de izquierda en el sistema político.

3.-Las violaciones de los DD.HH. en Argentina llevaron al juzgamiento y condena de los culpables, siendo posteriormente amnistiados. Para el caso uruguayo se optó por una ley de amnistía general para los responsables de violaciones a los DD.HH., medida que fue plebiscitada a instancia de la sociedad civil.

Se analizan las distintas repercusiones que tuvieron para la consolidación de los sistemas políticos.

4.- Tanto en Uruguay como en Argentina se generalizaron procesos electorales de "voto castigo" y alta rotatividad entre los votantes de los partidos tradicionales.

Pero mientras que en Argentina no se registra una pérdida relativa en el caudal electoral de los partidos tradicionales, en Uruguay la pérdida constante de votantes de los mismos en los últimos años es muy apreciable.

\section{ABSTRACT}

1.-Although Argentina underwent a fast democratization process, consolidation was not achieved and waves and breaking kept appearing.

Different from this case, the re-democratization process in Uruguay is much more slowly but could get a better consolidation in the long run.

2.-Argentina presented continuous waves all along its political history. In spite of this, the two-parties political system ("radicales" and "peronistas") without any leftist parties at all.

On the contrary, Uruguay registered huge changes in its party system. In fact, the two parties scheme led to a pluralist one, with an enormous increase and power of the left.

3.-Argentina because of human rights violations culpables were judge, being under amnesty afferwards. On the Uruguayan case general amnesty law was the choose it was aplied to human rights violations responsables and was plebiscitated among civil society.

The different consequences of these are analised about the consolidation political system.

4.- "Punishment voting" and high rotation between voters from traditional parties, are the recent and generalized processes in Argentina and Uruguay. A not slight difference should be remarked: in Argentina, the traditional parties have not decreased the total votes. In Uruguay, just the reverse: the less votes to this kind of parties have been acute during the last years. 